\title{
¿Spatial and Temporal Scales of Sverdrup Balance*
}

\author{
MATTHEW D. THOMAS ${ }^{+}$ \\ School of Environmental Sciences, University of East Anglia, Norwich, United Kingdom
}

Agatha M. De Boer

Department of Geological Sciences and Bolin Centre for Climate Research, Stockholm University, Stockholm, Sweden

HELEN L. JOHNSON

Department of Earth Sciences, University of Oxford, Oxford, United Kingdom

DAVID P. STEVENS

School of Mathematics, University of East Anglia, Norwich, United Kingdom

(Manuscript received 7 September 2013, in final form 5 June 2014)

\begin{abstract}
Sverdrup balance underlies much of the theory of ocean circulation and provides a potential tool for describing the interior ocean transport from only the wind stress. Using both a model state estimate and an eddypermitting coupled climate model, this study assesses to what extent and over what spatial and temporal scales Sverdrup balance describes the meridional transport. The authors find that Sverdrup balance holds to first order in the interior subtropical ocean when considered at spatial scales greater than approximately $5^{\circ}$. Outside the subtropics, in western boundary currents and at short spatial scales, significant departures occur due to failures in both the assumptions that there is a level of no motion at some depth and that the vorticity equation is linear. Despite the ocean transport adjustment occurring on time scales consistent with the basin-crossing times for Rossby waves, as predicted by theory, Sverdrup balance gives a useful measure of the subtropical circulation after only a few years. This is because the interannual transport variability is small compared to the mean transports. The vorticity input to the deep ocean by the interaction between deep currents and topography is found to be very large in both models. These deep transports, however, are separated from upper-layer transports that are in Sverdrup balance when considered over large scales.
\end{abstract}

\section{Introduction}

Sverdrup balance is one of the most important underpinnings for oceanic theory, contributing to much of the historical understanding of the time-mean circulation of

D Denotes Open Access content.

\footnotetext{
* Supplemental information related to this paper is available at the Journals Online website: http://dx.doi.org/10.1175/JPO-D-13-0192.s1.

${ }^{+}$Current affiliation: Laboratoire de Physique des Océans, CNRSIfremer-IRD-UBO, Plouzané, France.
}

Corresponding author address: Matthew D. Thomas, Laboratoire de Physique des Océans, CNRS-Ifremer-IRD-UBO, Pointe du Diable, 29280 Plouzané, France.

E-mail: matthew.thomas@ifremer.fr ocean gyres (Stommel 1948; Anderson and Killworth 1977; Luyten et al. 1983). Sverdrup balance describes a simple yet powerful balance between the wind stress curl and the depth-integrated meridional transport in the ocean. However, it has been difficult to provide strong observational evidence for its validity due to a lack of long-term ocean observations. It was originally validated using thermal wind geostrophic currents calculated relative to an assumed level of no motion at $500 \mathrm{db}$ (Sverdrup 1947). Later studies have highlighted the need to test the assumptions that are made in the formulation of Sverdrup balance, that is, that a level of no vertical motion (LONM) exists in the ocean, and that the ocean vorticity balance is linear (Wunsch and Roemmich 1985; Lu and Stammer 2004).

Studies of Sverdrup balance using hydrographic data have suggested that the interior subtropical upper ocean 
(from the surface to approximately 1-km depth) is in Sverdrup balance to a good order of approximation when considered over horizontal scales of a few degrees or more, but not at smaller scales (Hautala et al. 1994; Roemmich and Wunsch 1985; Gray and Riser 2014). Small-scale deviations from Sverdrup balance have been attributed to a breakdown in the assumption that the nonlinear vorticity terms are small (Lu and Stammer 2004). In western boundary regions (Roemmich and Wunsch 1985; Bryan et al. 1995; Gray and Riser 2014) and in regions poleward of the subtropics (Luyten et al. 1985; Bryan et al. 1995; Lu and Stammer 2004; Gray and Riser 2014), the ocean deviates significantly from Sverdrup balance due to enhanced nonlinear eddy activity and deep currents that ensure there is not a LONM. Most studies have focused on the Atlantic, but the findings are consistent for the Pacific (Hautala et al. 1994; Jiang et al. 2006) and Indian Oceans (Godfrey and Golding 1981).

Schmitz et al. (1992) summarized the zonally integrated Sverdrup balance in the North Atlantic using the results from hydrographic surveys at $24^{\circ} \mathrm{N}$ (Leetmaa et al. 1977; Stommel et al. 1978; Roemmich and Wunsch 1985) and from maps of the wind-derived Sverdrup transport streamfunction (Leetmaa and Bunker 1978; Böning et al. 1991). They concluded that the zonally integrated, upper-interior North Atlantic along $24^{\circ} \mathrm{N}$ (east of the Antilles Current) is consistent with estimations from Sverdrup balance. Wind-derived estimates of the southward interior ocean transports are found to balance the combined northward western boundary currents (the Florida Straits and Antilles Currents) and the southward deep currents.

Care is required when interpreting observational evidence of Sverdrup balance due to assumptions made on the consistency between wind stress and ocean data. The variety of available wind products can produce very different time-dependent (Landsteiner et al. 1990; Böning et al. 1991; Bryan et al. 1995; Townsend et al. 2000) and time-mean (Josey et al. 2002; Aoki and Kutsuwada 2008) wind stresses.

Many past studies of Sverdrup balance have limited their analysis to the full-depth integrated Sverdrup balance (Zhang and Vallis 2007; Hughes and de Cuevas 2001), specific regions (Schmitz et al. 1992; Hautala et al. 1994), or instantaneous sections (Wunsch and Roemmich 1985). Recently, Wunsch (2011) showed that large parts of the interior subtropical ocean are in Sverdrup balance when considered in a 16-yr time mean of the Estimating the Circulation and Climate of the Oceans-Global Ocean Data Assimilation Experiment (ECCO-GODAE) state estimate. Strong observational evidence that Sverdrup balance holds over most of the subtropics has also recently been produced using the Argo profiling array (Gray and Riser 2014). Here we expand on these studies by assessing over what space and time scales Sverdrup balance holds. The focus is on the interior subtropical ocean away from the western boundary where Sverdrup balance is already known to break down.

Two models have been used for this study, a 15-yr run of the ECCO-GODAE (Wunsch and Heimbach 2007) version 3 state estimate and a 120 -yr control run of the High-Resolution Global Environment Model (HiGEM; Shaffrey et al. 2009) eddy-permitting coupled model. ECCO-GODAE is a good framework within which to undertake such an investigation because it combines both observational and model attributes within a dynamically consistent environment. We have therefore used ECCO-GODAE to analyze all terms in the vorticity equation and to draw the main conclusions regarding the time-mean Sverdrup balance. We have then used the longer HiGEM run to confirm the main conclusions drawn from ECCOGODAE and also to investigate the time scales of Sverdrup balance.

In the following section, the background theory is described along with a discussion of the assumptions made in formulating Sverdrup balance. In section 3, we describe the models, followed by an explanation of our methodology in section 4 . Section 5 describes the results from ECCO-GODAE, and section 6 describes the results from HiGEM. Section 7 summarizes the key findings and provides a discussion of their robustness and the relevance to real world dynamics.

\section{Theoretical discussion}

The time-mean vorticity budget of the ocean is described by the curl of the steady-state momentum equation, which, under the Boussinesq approximation, the vertical component is written

$$
\begin{aligned}
\beta v= & f \partial_{z} w+\hat{\mathbf{k}} \cdot \nabla \times\left[\left(1 / \rho_{0}\right) \partial_{z} \boldsymbol{\tau}\right. \\
& \left.+\nabla \cdot\left(A_{H} \nabla \mathbf{u}_{H}\right)-(\mathbf{u} \cdot \nabla) \mathbf{u}\right],
\end{aligned}
$$

where $f$ is the Coriolis parameter, $\rho_{0}$ is a constant reference density, $\beta=\partial_{y} f$, and $\mathbf{u}$ and $\mathbf{u}_{H}$ are, respectively, the three-dimensional and horizontal velocity vectors of which $u, v$, and $w$ are the zonal, meridional, and vertical components. The horizontal and vertical viscosity coefficients are represented by $A_{H}$ and $A_{V}$, respectively, and $\boldsymbol{\tau}=\rho_{0} A_{V} \partial_{z} \mathbf{u}$ is the frictional stress. The vector $\hat{\mathbf{k}}$ is the vertical unit vector. The first two terms are the geostrophic vorticity balance, and the third, fourth, and fifth terms are the curls of the vertical eddy viscosity, horizontal eddy viscosity, and nonlinear advection, respectively. 
Integrating Eq. (1) from the surface $s$ to some middepth (and temporally and spatially constant) level $h$ and rearranging for the depth-integrated meridional velocity $V$, we find that

$$
V=\left(1 / \rho_{0} \beta\right) \hat{\mathbf{k}} \cdot \nabla \times \boldsymbol{\tau}_{s}-(f / \beta) w_{h}+(1 / \beta) \hat{\mathbf{k}} \cdot \nabla \times \int_{-h}^{s} \nabla \cdot\left(A_{H} \nabla \mathbf{u}_{H}\right) \mathrm{d} z-(1 / \beta) \hat{\mathbf{k}} \cdot \boldsymbol{\nabla} \times \int_{-h}^{s}(\mathbf{u} \cdot \nabla) \mathbf{u} \mathrm{d} z
$$

It has been assumed that there is no vertical flow through the surface, that bottom drag is negligible, and that the vertical eddy viscosity is negligible at depths below the thermocline. These are reasonable and tested (not shown) assumptions for the ECCOGODAE state estimate. The first two terms illustrate the Sverdrup balance, which would hold if all other terms were negligible. This states that any time-mean meridional transport above a LONM (where $w_{h}=0$ ) is solely a consequence of a nonzero wind stress curl. Physically, the squashing and stretching of fluid columns (vortex stretching) caused by wind-driven Ekman pumping is compensated by a change in latitude in order to conserve potential vorticity. The second term on the RHS, $-f w_{h} / \beta$, is here called the LONM error, $\Delta_{\text {LONM }}$. The remaining terms on the RHS, the curl of the horizontal viscosity term $(1 / \beta) \hat{\mathbf{k}} \cdot \nabla \times \mathrm{HV}$ and nonlinear advection term $-(1 / \beta) \hat{\mathbf{k}} \cdot \boldsymbol{\nabla} \times \mathrm{ADV}$ are together called the linear vorticity error $\Delta_{\mathrm{LV}}$. We name the combined two error components the Sverdrup error, $\Delta_{\mathrm{SE}}=$ $(1 / \beta) \hat{\mathbf{k}} \cdot \nabla \times(\mathrm{HV}-\mathrm{ADV})-f w_{h} / \beta$. Hereinafter, the LHS of Eq. (2) is referred to as the ocean transport, and the first term on the RHS as the Sverdrup transport.

Several different definitions of Sverdrup balance can be found in the literature, which include the geostrophic vorticity balance, the depth-integrated geostrophic vorticity balance integrated to the sea floor, and the depthintegrated geostrophic vorticity balance integrated to an assumed LONM. In this paper, we consider only the latter.

\section{Description of models}

We have used two models in this study. The first is the ocean state estimation product, ECCO-GODAE, version 3 , which incorporates ocean observations into the solution of the Massachusetts Institute of Technology general circulation model (MITgcm; Marshall et al. 1997). The second is the high-resolution coupled climate model HiGEM (Shaffrey et al. 2009; Roberts et al. 2009).

The ECCO product provides four-dimensional estimates of oceanic variables that would otherwise be difficult to produce from observations alone. The model solution is optimized by using a model adjoint that reduces the model-to-data misfit with an iterative gradient descent approach (Marotzke et al. 1999) and provides terms in the momentum (and vorticity) equation that are dynamically consistent with each other. Ocean observations employed in the model solution include satellitebased sea surface height, temperature, wind stress, and geoid products, as well as in situ collected observations (from Argo floats and hydrographic sections) of salinity and temperature. See Wunsch and Heimbach (2007) for a more complete description of the data included and methods of incorporation. The horizontal resolution is $1^{\circ}$ in longitude and latitude. There are 23 levels in the vertical, unevenly spaced to give higher surface resolution. The meridional domain ranges from $80^{\circ} \mathrm{S}$ to $80^{\circ} \mathrm{N}$. Output is provided as monthly means from January 1992 to December 2007 (although year 1992 has been removed to avoid any residual model spinup). Horizontal viscosity is parameterized in the model as a Laplacian and solved explicitly with a coefficient of $10^{4} \mathrm{~m}^{2} \mathrm{~s}^{-1}$. Vertical viscosity is solved implicitly according to the $K$-profile parameterization (KPP) of Large et al. (1994) with the background viscosity coefficient set at $10^{-3} \mathrm{~m}^{2} \mathrm{~s}^{-1}$. The methods we have used for calculating vorticity in ECCOGODAE are not straightforward and are described in section 1 of the supplementary material.

HiGEM is a coupled atmosphere-ocean-sea ice model based on the Met Office Hadley Centre Global Environment Model, version 1 (HadGEM1; Johns et al. 2006), but uses a higher horizontal resolution of $0.83^{\circ}$ latitude $\times$ $1^{\circ}$ longitude in the atmosphere and an eddy-permitting $1 / 3^{\circ} \times 1 / 3^{\circ}$ resolution ocean. HiGEM also has a higher vertical resolution, with 40 vertical levels in the ocean and 38 vertical levels in the atmosphere, each unevenly spaced to allow higher surface boundary layer resolution. It uses a spherical latitude-longitude grid between $90^{\circ} \mathrm{S}$ and $90^{\circ} \mathrm{N}$. Initial conditions are from the World Ocean Atlas 2001 (Conkright et al. 2002) for the ocean and European Centre for Medium-Range Weather Forecasts (ECMWF) analysis for the atmosphere. We have used annual-mean output from a 150-yr control integration in which greenhouse gases are kept constant at present-day concentrations. Significant initial adjustments take place over the first $30 \mathrm{yr}$, and therefore these have been discarded. Analysis in this model focuses on the Sverdrup balance terms, $V$ and $\left(1 / \rho_{0} \beta\right) \hat{\mathbf{k}} \cdot \nabla \times \boldsymbol{\tau}_{s}$, and their difference, $\Delta_{\mathrm{SE}}$. The very different resolutions and forcings of the models mean that we can assess the robustness of the major results of this study by comparing the two models. 


\section{Methodology}

\section{a. Defining the study domain}

In this study, we are interested in how well Sverdrup balance holds in the regions where one might expect it to hold, and we therefore ignore regions where we know the Sverdrup errors are very large. In light of the breakdown of Sverdrup balance at western boundaries and at high latitudes, we have defined a mask to exclude regions between the western boundary and $1000 \mathrm{~km}$ east of the 2000-m depth contour. Regions poleward of $35^{\circ}$ latitude have also been masked out in the horizontal integrals and some of the figures that follow. These limits are chosen qualitatively based on the data. The results presented throughout this study are largely insensitive to changes up to the order of $200 \mathrm{~km}$ in the size of the mask at the boundaries. Regions lying within the masked regions have been excluded in any calculations of integrated or averaged quantities. Regions outside of the mask are considered to be the ocean interior. The mask boundary is displayed as a yellow border in maps of transport (e.g., shown below in Fig. 2e).

\section{b. Sverdrup balance metrics}

We have defined two single-value metrics to characterize how well Sverdrup balance holds over the whole domain. The first one indicates how well Sverdrup balance holds in a pointwise sense, and the second one tests Sverdrup balance on a basinwide scale, where the transport is zonally integrated. Both definitions of Sverdrup balance are of interest since each one provides us with a different understanding of the system. The zonally integrated metric is the more important in considerations of how Sverdrup balance would affect, for example, basinwide mass balance (de Boer and Johnson 2007; Thomas et al. 2012), and the pointwise metric is more important in considerations of how Sverdrup balance would affect, for example, the heat transport.

Of interest is the magnitude of the Sverdrup error relative to the magnitude of the Sverdrup transport. Therefore the pointwise metric $M_{\mathrm{pw}}$ is defined as the horizontal-mean (i.e., zonal and meridional mean) of the absolute pointwise Sverdrup error divided by the horizontal-mean absolute pointwise Sverdrup transport. Likewise, the zonally integrated metric $M_{\mathrm{zi}}$ is the meridional-mean, absolute zonally integrated Sverdrup error divided by the meridional-mean, absolute zonally integrated Sverdrup transport, or

$$
M_{\mathrm{pw}}=\frac{\left\langle\left\langle\left|\Delta_{\mathrm{SE}}\right|\right\rangle_{y}\right\rangle_{x}}{\left\langle\left\langle\left|\frac{1}{\rho_{0} \beta} \hat{\mathbf{k}} \cdot \nabla \times \boldsymbol{\tau}_{s}\right|\right\rangle_{y}\right\rangle_{x}} \text {, and }
$$

$$
M_{\mathrm{zi}}=\frac{\left\langle\left|\int_{x_{\text {west }}}^{x_{\text {east }}} \Delta_{\mathrm{SE}} \mathrm{d} x\right|\right\rangle_{y}}{\left\langle\left|\int_{x_{\text {west }}}^{x_{\text {east }}} \frac{1}{\rho_{0} \beta} \hat{\mathbf{k}} \cdot \nabla \times \tau_{s} \mathrm{~d} x\right|\right\rangle_{y}},
$$

where the angle brackets represent averaging in the zonal (subscript $x$ ) and meridional (subscript $y$ ) directions. By taking a meridional average, the problem of dividing by localized regions of zero (or small) Sverdrup transport is reduced. As such, the metrics are domain dependent and should be interpreted accordingly. Both metrics are applied to all interior ocean unmasked regions. Values are expressed as percentages, where $0 \%$ implies a perfect balance and 100\% implies the errors are as large as the Sverdrup transport. To assess and compare Sverdrup balance over different spatial scales, 2D horizontal boxcar smoothing functions of different sizes (as stated in the relevant sections) have been applied to the transport fields prior to the application of each metric. Note that if the ocean transports are instead used in the denominator then the conclusions of the study do not change.

The metrics here are sensitive to a small number of grid cells with anomalously large Sverdrup errors that remain after the application of the mask. These grid points are mostly located on the domain boundaries or around islands and act to bias the metrics in favor of an imbalance in Sverdrup balance. Therefore, to ignore strong outliers, the 99th percentile of the Sverdrup error field has been removed in any calculation of integrated transport.

Since the assumptions that go into Sverdrup balance (or geostrophic vorticity balance) can never be perfect, it becomes necessary, in any study aiming to quantify how good the balance is, to define a threshold at which the balance of terms can be said to hold to a good order of approximation. In this study, "a good order of approximation" is defined as being achieved when the magnitude of the Sverdrup metrics is $30 \%$ or less.

\section{Vorticity Budgets in ECCO-GODAE}

\section{a. Sensitivity to the level of no motion}

Here we describe the sensitivity of Sverdrup balance to the choice of integration depth. Such a depth can be a flat plane or a more complicated surface with depths that are dependent on geographic location (geovarying).

The simplest method (here referred to as $V_{\text {plane }}$ ) is to assume a single integration depth that is independent of latitude or longitude. Figure 1a shows how the Sverdrup 

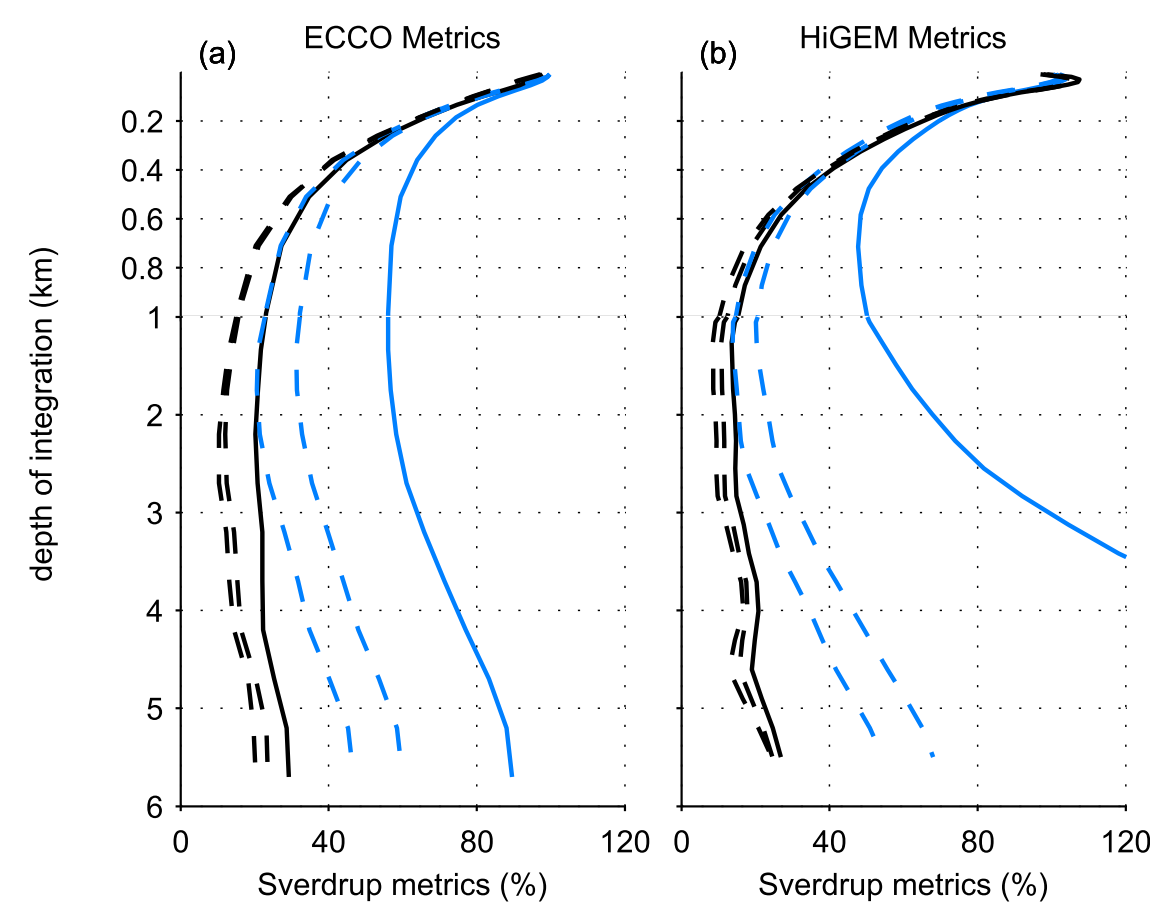

FIG. 1. Sverdrup metrics $M_{\mathrm{pw}}$ (blue) and $M_{\mathrm{zi}}$ (black) vs integration depth for (a) ECCOGODAE and (b) HiGEM. The metrics are applied to unmasked regions between $35^{\circ} \mathrm{S}$ and $35^{\circ} \mathrm{N}$. Solid lines represent unsmoothed values and dashed lines represent 2D smoothing of the transport fields at $5^{\circ}$ and $9^{\circ}$. Note the change in vertical scale at $1-\mathrm{km}$ depth.

balance metrics, $M_{\mathrm{pw}}$ [blue line; Eq. (3)] and $M_{\mathrm{zi}}$ [black line; Eq. (4)], change with the choice of integration depth (i.e., the depth to which the ocean transport is integrated from the surface down) when applied over the unmasked subtropical domain of ECCO-GODAE. The first metric, $M_{\mathrm{pw}}$, describes how well Sverdrup balance holds on a pointwise basis and the second, $M_{\mathrm{zi}}$, describes how it holds on a zonally integrated basis. Both metrics initially reduce with integration depth before increasing again after the optimal levels of 1100 and $2600 \mathrm{~m}$ are reached for $M_{\mathrm{pw}}$ and $M_{\mathrm{zi}}$, respectively. At these depths, $M_{\mathrm{pw}}$ is $56 \%$ (i.e., the Sverdrup error is $56 \%$ of the magnitude of the Sverdrup transport) and $M_{\mathrm{zi}}$ is $20 \%$. The initial reduction corresponds to an increasing amount of wind-driven flow being included in the depth integral. The later increase corresponds to an increasing amount of non-wind-driven flow being included in the integral (by non-wind-driven flow we mean that flow that does not respond directly to the input of vorticity by the wind stress curl). Prior application of smoothing at $5^{\circ}$ or $9^{\circ}$ to the pointwise transports pushes the minimum to a deeper level of $1400 \mathrm{~m}$. Therefore, on large scales, a depth plane that can be considered to lie between the bulk of the wind-driven and deep transports is approximately $1400 \mathrm{~m}$ (though any depth between approximately 500 and $3000 \mathrm{~m}$ could be used with little practical difference). The 15 -yr time-mean ocean transport $(V)$ depth-integrated to $1400 \mathrm{~m}$ is shown in Fig. $2 \mathrm{a}$ along with the Sverdrup transport $\left[\left(1 / \rho_{0} \beta\right) \hat{\mathbf{k}} \cdot \boldsymbol{\nabla} \times \boldsymbol{\tau}_{s} ;\right.$ Fig. $2 c]$ and the Sverdrup error $\left[\left(1 / \rho_{0} \beta\right) \hat{\mathbf{k}} \cdot \nabla \times \boldsymbol{\tau}_{s}-V\right.$; Fig. 2e].

The $V_{\text {plane }}$ method of using a single depth plane for an integration depth is a relatively simple approach to calculate Sverdrup balance and the domain optimal depth to minimize $\Delta_{\mathrm{SE}}$ is unlikely to be the optimum depth locally. We have developed various methods of determining a physically meaningful geovarying LONM that uses potential density surfaces and surfaces where horizontal and vertical velocities and their vertical derivatives are small. In section 2 of the supplementary section, we demonstrate that the Sverdrup error is not very sensitive to the chosen LONM as long as the ocean is everywhere integrated to below the main thermocline depth, but not so deep that non-wind-driven deep transports are included. All analysis of Sverdrup balance throughout the rest of the manuscript therefore uses a simple integration depth plane at $1400 \mathrm{~m}$ depth.

\section{b. Spatial scales of Sverdrup balance}

We now assess where Sverdrup balance holds and how well it holds when considered globally over different scales of spatial smoothing. As expected, the ocean 
(a)

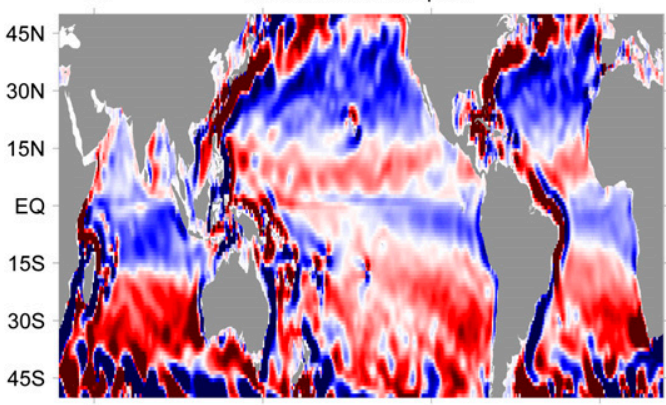

(c)

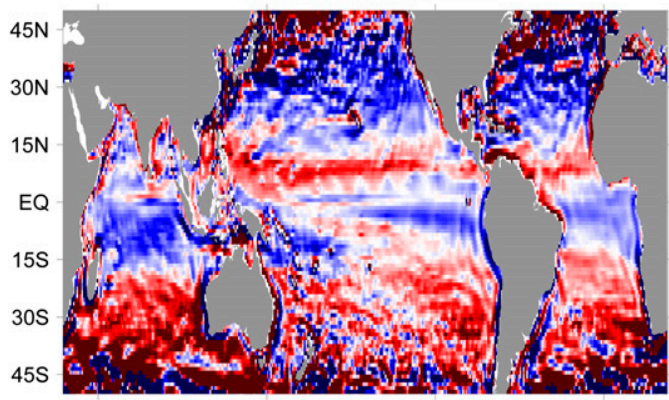

(e)

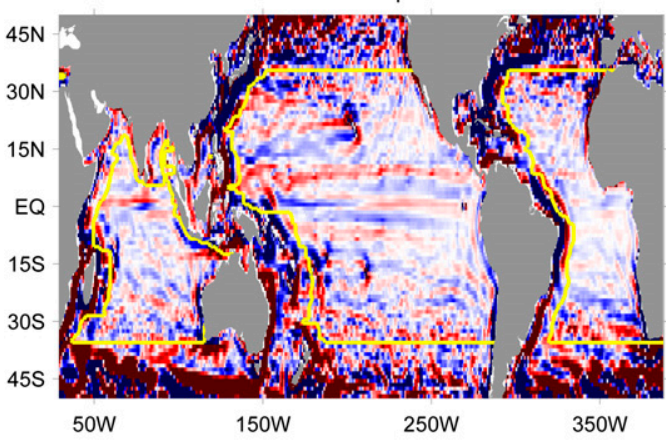

(b)

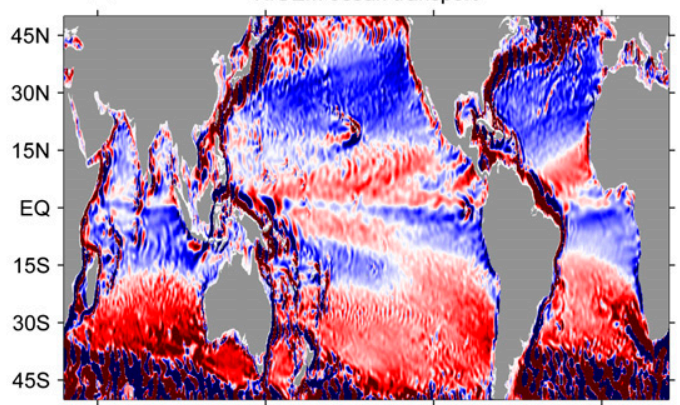

(d)

HiGEM Sverdrup transport

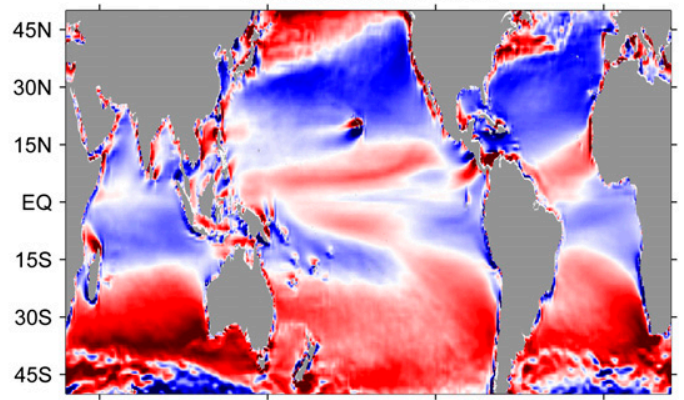

(f)

HiGEM Sverdrup error

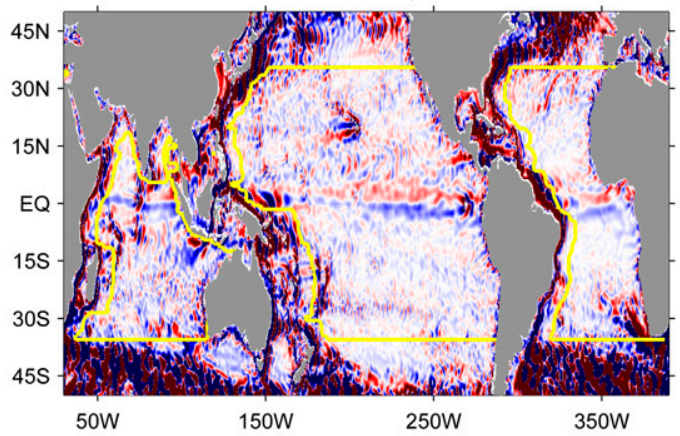

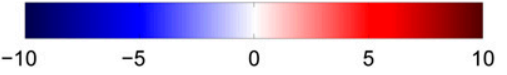

FIG. 2. Vorticity terms $\left(\mathrm{m}^{2} \mathrm{~s}^{-1}\right)$ in the 15-yr time-averaged Sverdrup balance in (left) ECCO-GODAE and (right) HiGEM: (a),(b) $V$ (using integration depths of 1400 and $1000 \mathrm{~m}$, respectively), (c),(d) $\left(1 / \rho_{0} \beta\right) \hat{\mathbf{k}} \cdot \nabla \times \boldsymbol{\tau}_{s}$, and (e),(f) the Sverdrup error, $\left(1 / \rho_{0} \beta\right) \hat{\mathbf{k}} \cdot \boldsymbol{\nabla} \times \boldsymbol{\tau}_{s}-V$. The yellow border in (e) and (f) indicates the edge of the masked regions not included in the determination of any integrated quantities.

transport (Fig. 2a) and Sverdrup transport (Fig. 2c) fields exhibit similar large-scale structure at low latitudes, such as equatorward subtropical mass transport and poleward transport in the tropics, but diverge in the western boundaries and high latitudes (Pedlosky 1987; Bryan et al. 1995; Gent et al. 2001). These latter regions are mostly excluded by the mask shown in Fig. 2e. The regions where Sverdrup balance does not describe the large-scale flow in the model closely resemble recent calculations of Sverdrup balance made using Argo floats (Gray and Riser 2014).

Sverdrup errors close to the eastern boundaries are in places large in all ocean basins other than the North
Pacific and North Indian Ocean, as also noted in Wunsch (2011). Additional large Sverdrup errors occur at the island chains of Hawaii in the North Pacific and French Polynesia in the South Pacific Ocean. In each case large Sverdrup and model transports are arranged in dipole patterns around the island chains. However, the dipole patterns are not similarly oriented and so the pointwise Sverdrup errors (i.e., the difference between them) in this region are large. Examining this behavior is beyond the scope of the current study.

In our unmasked domain, particularly at higher latitudes, the wind-derived Sverdrup transport contains small-scale variability that is not present in the ocean 

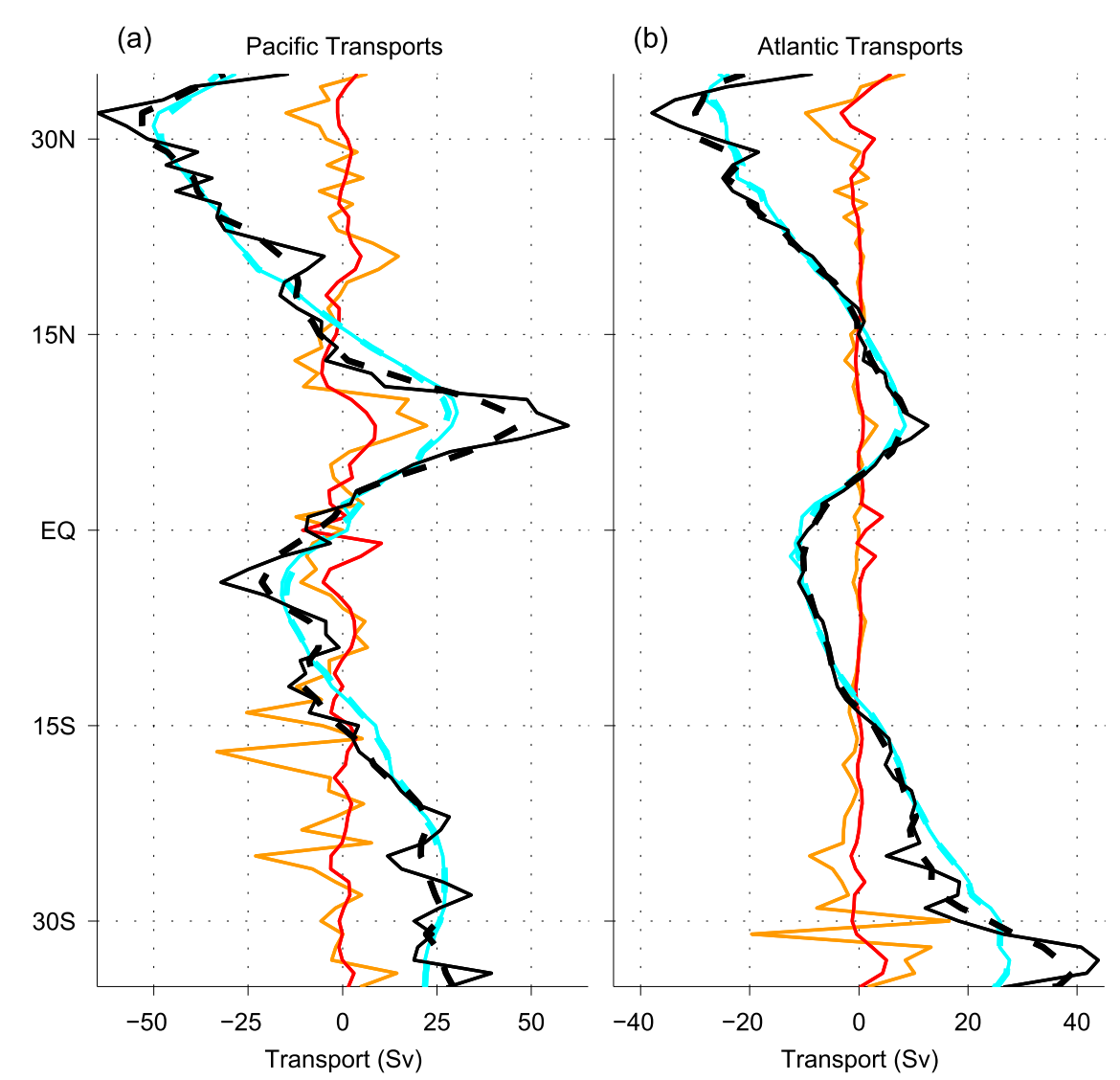

FIG. 3. Zonally integrated values (Sv) of the terms in Sverdrup balance in ECCO-GODAE: $V$ (using an integration depth of $1400 \mathrm{~m}$; thin cyan line) and $\left(1 / \rho_{0} \beta\right) \hat{\mathbf{k}} \cdot \nabla \times \boldsymbol{\tau}_{s}$ (thin black line) vs latitude in the (a) Pacific and (b) Atlantic. The other thin lines represent the linear vorticity error $\Delta_{\mathrm{LV}}$ (red) and LONM error $\Delta_{\text {LONM }}$ (orange; see text for how these are derived). Thick dashed lines represent $2 \mathrm{D}$ smoothing of the transport fields over $5^{\circ}$. Only values outside of the unmasked region shown in Fig. 2e are used in the integrals.

transport (Fig. 2c). This is consistent throughout all ocean basins. Although persistent small-scale variability has been reported from 4-yr mean satellite scatterometry data (Chelton et al. 2004), the variability in ECCOGODAE is large in comparison (see section 6a and the conclusions for a further discussion of this variability). Despite the difference between Sverdrup and model transport on small scales, when the transports are integrated across the interior ocean domains of the Pacific (Fig. 3a) and Atlantic (Fig. 3b), the Sverdrup balance terms are in good agreement, particularly if we apply $5^{\circ}$ meridional smoothing (thick dashed lines). The smallscale differences, including those at the eastern boundary, are therefore largely reduced following integration or smoothing.

Large deviations remain in the smoothed curves of zonally integrated Sverdrup balance at approximately $8^{\circ} \mathrm{N}$ in the Pacific Ocean (Fig. 3a) and in the South Atlantic region to the south of $30^{\circ} \mathrm{S}$ (Fig. 3b). The first of these is associated with Sverdrup transports in the trade wind belt that are stronger than model transports here. The second is related to the Agulhas Current leakage into the South Atlantic Ocean.

We showed in the previous section that Sverdrup balance holds poorly in the subtropics when evaluated pointwise, with the optimum $M_{\mathrm{pw}}$ value as high as $56 \%$ (Fig. 1a). The poor balance is the result of the smallscale variability present in the Sverdrup transport and because of the large Sverdrup errors near islands and the east coast. Prior application of $5^{\circ}$ and $9^{\circ}$ horizontal 2D smoothing to the transport fields greatly reduces $M_{\mathrm{pw}}$ to $31 \%$ and $25 \%$, respectively (Fig. 1a). Further increasing the smoothing scale continues to reduce $M_{\mathrm{pw}}$ up until scales of about $15^{\circ}$, at which it is $15 \%$. Only small incremental improvements in $M_{\mathrm{pw}}$ are gained by further smoothing beyond this scale. Sverdrup balance in ECCO-GODAE therefore holds to a good order of approximation at spatial scales greater than $5^{\circ}$, but not at 
scales smaller than this. These findings support earlier studies based on hydrographic measurements (Hautala et al. 1994; Roemmich and Wunsch 1985).

The optimum zonally integrated unsmoothed metric $M_{\mathrm{zi}}$ is $20 \%$ for an integration depth of $1400 \mathrm{~m}$. The reduced size of $M_{\mathrm{zi}}$ compared to $M_{\mathrm{pw}}$ is because the zonal integration removes small-scale zonal variability. For this reason, the smoothing is less effective with $M_{\mathrm{zi}}$, reducing it to $13 \%$ at $5^{\circ}$ smoothing. Smoothing beyond approximately $9^{\circ}$, where $M_{\mathrm{zi}}$ is $11 \%$, makes only small improvements. The zonally integrated subtropical ocean is therefore in Sverdrup balance to a good order of approximation, even when unsmoothed. Interestingly, while there are large deep transports that put a pointwise consideration of the ocean out of Sverdrup balance when integrated to the bottom, the deep transports largely cancel out once zonally integrated across the unmasked domain. This means that the zonally integrated Sverdrup balance holds to a good approximation when using the full-depth-integrated transports.

\section{c. Contributions to Sverdrup error}

As discussed in section 2, the Sverdrup error (Fig. 2e) can be decomposed into two component errors: the LONM error $\Delta_{\text {LONM }}$ (Fig. 4a) and the linear vorticity error $\Delta_{\mathrm{LV}}$. The dominant term of the two is $\Delta_{\mathrm{LONM}}$, which is on average approximately twice as large as $\Delta_{\mathrm{LV}}$ in the domain shown (according to the mean absolute of the values). The linear vorticity error can be further split into two component parts: the horizontal viscosity term $(1 / \beta) \hat{\mathbf{k}} \cdot \boldsymbol{\nabla} \times \mathrm{HV}$ (Fig. $4 \mathrm{c})$ and the advection term $(1 / \beta) \hat{\mathbf{k}}$. $\nabla \times$ ADV (Fig. 4e). The advection component makes contributions in the western boundary currents, in nearequatorial regions, and at high latitudes. Although advection contributions close to the equator are significant, as was also found by Kessler et al. (2003), the horizontal viscosity is the major contributor to the linear vorticity error throughout the interior subtropics in ECCO-GODAE. Zonal integrals of both $\Delta_{\mathrm{LV}}$ (red line) and $\Delta_{\text {LONM }}$ (orange line) are shown in Fig. 3.

The two error components, $\Delta_{\mathrm{LV}}$ and $\Delta_{\mathrm{LONM}}$, each increase in magnitude at higher latitudes and display a spatial pattern similar to each other. At $5^{\circ}$ smoothing the similarity in geographical pattern between the two is retained, and the approximately two to one ratio described above continues to hold (Figs. 4b,d). This is also true for stronger smoothing levels. Their relative contributions to the Sverdrup error therefore do not greatly change with smoothing.

Values of $\Delta_{\mathrm{LV}}$ and $\Delta_{\mathrm{LONM}}$ presented here differ from those presented in Lu and Stammer (2004), who use an earlier version of the ECCO-GODAE model. Lu and Stammer (2004) attribute most of the error in the interior subtropics within $35^{\circ}$ of the equator to the linear vorticity error, composed mostly of $\hat{\mathbf{k}} \cdot \nabla \times \mathrm{ADV}$, and suggest that $\Delta_{\text {LONM }}$ only becomes significant poleward of $20^{\circ}$ latitude. This may be due to differences in the methods used to calculate vorticity in ECCO-GODAE. The reader is referred to the section 1 of the supplementary material for a discussion of how the vorticity equation is calculated in this study.

In ECCO-GODAE, the errors from assuming geostrophy $\left[f \hat{\mathbf{k}} \times \mathbf{u}=-\left(1 / \rho_{0}\right) \nabla_{h} p\right]$ are relatively smaller in the momentum equation than are those from assuming linear vorticity $\left(\beta v=f \partial_{z} w\right)$ in the vorticity equation. This is despite geostrophic vorticity balance being derived from the curl of geostrophy and is possibly due to amplification of the small-scale ageostrophic terms following the horizontal differentiation in the calculation of the curl (Kessler et al. 2003). To demonstrate the effect of this, Fig. 5 shows, at a depth of 310 m, 15-yr time means of the zonal geostrophic momentum terms (Fig. 5a) $f v$, (Fig. 5c) $-\left(1 / \rho_{0}\right) \partial_{x} p$, and (Fig. 5e) their difference $\left[f v+\left(1 / \rho_{0}\right) \partial_{x} p\right]$ and of the linear vorticity terms (Fig. 5b) $\beta v$, (Fig. 5d) $f \partial_{z} w$, and (Fig. 5f) their difference $\left(\beta v-f \partial_{z} w\right)$. While the residual of the geostrophic terms (the sum of the ageostrophic terms) is two orders of magnitude smaller than either of the geostrophic terms, the linear vorticity error is only one order of magnitude smaller than the linear vorticity terms at this depth (note the different color axis scales used in each subplot).

\section{d. Deep-ocean processes}

Considerable depth-integrated transports exist in the model below 1400-m depth (Fig. 6a) that are, in places, comparable in magnitude to the upper-ocean transports (Fig. 2a). In the unmasked domain, the mean absolute magnitude of the depth-integrated transports below $1400 \mathrm{~m}$ is $68 \%$ of the size of the equivalent in the upper $1400 \mathrm{~m}$. If the deep ocean is in geostrophic vorticity balance, the meridional transports imply that there are divergent vertical velocities. Since Sverdrup errors become very large when vertically integrating to the deep ocean (Fig. 1), it is likely that the meridional flow is forced by vertical velocities induced by the interaction between horizontal flow and bottom topography. This leads to bottom pressure torque (BPT) that can be calculated as the full-depth-integrated pressure term in the momentum equation (Hughes and de Cuevas 2001):

$$
\mathrm{BPT}=\hat{\mathbf{k}} \cdot \nabla \times \int_{-H}^{s} \frac{\nabla_{h} p}{\rho_{0}} d z,
$$

where pressure $p$ is integrated from the surface $s$ to the sea floor at depth $H$. The operator $\nabla_{h}$ is the horizontal gradient operator. It can be shown using the kinematic 
(a)

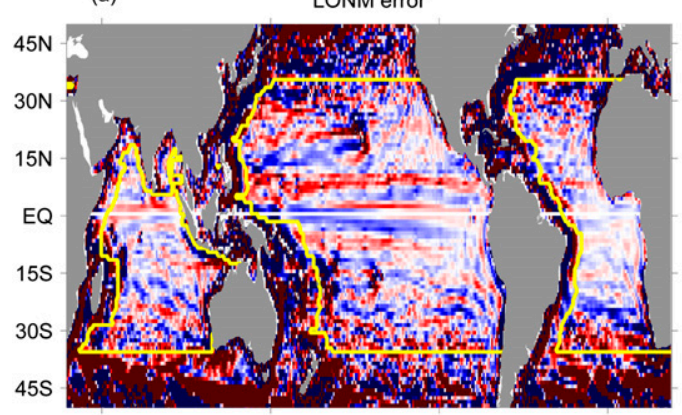

(c)

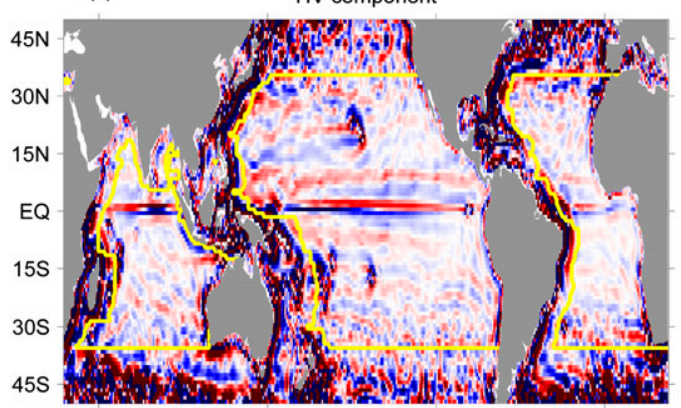

(e)

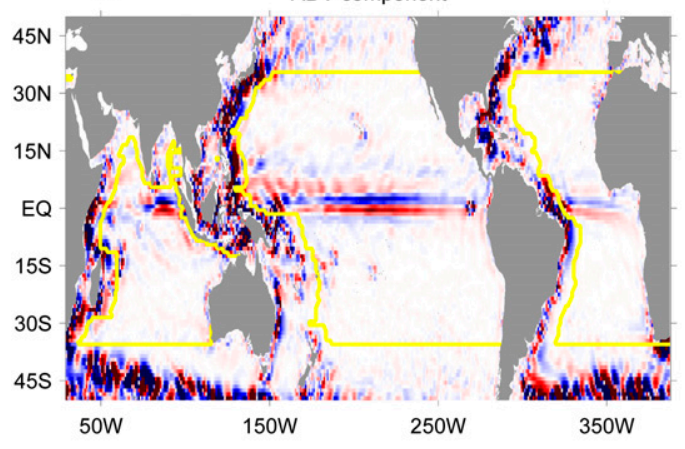

(b)

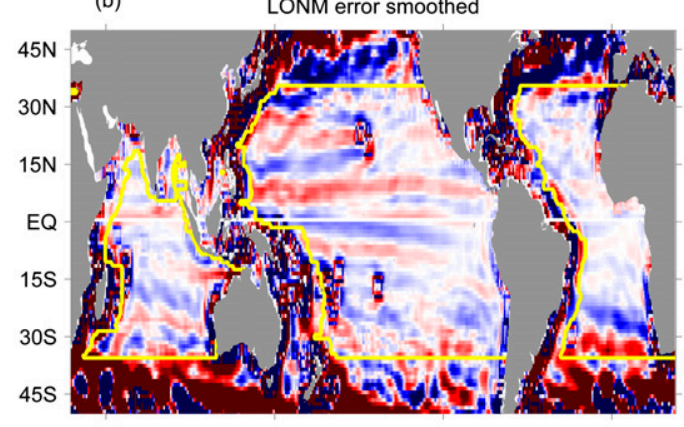

(d)

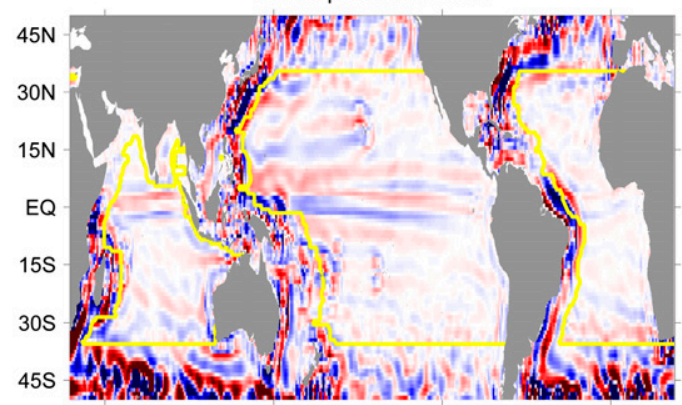

(f)

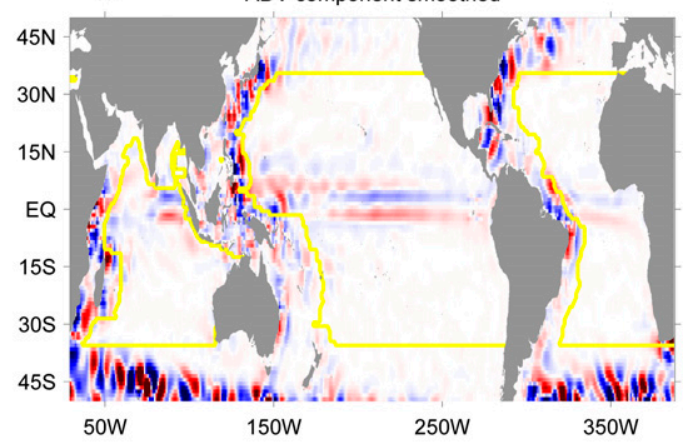

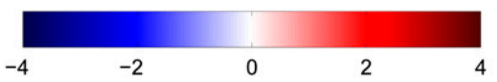

FIG. 4. (left) Unsmoothed and (right) $5^{\circ}$ smoothed component contributions $\left(\mathrm{m}^{2} \mathrm{~s}^{-1}\right)$ to the Sverdrup error $\Delta_{\mathrm{SE}}$ in ECCO-GODAE. (a),(b) LONM error, $\Delta_{\mathrm{LONM}}\left(f w_{h} / \beta\right),(\mathrm{c}),(\mathrm{d})[(1 / \beta) \hat{\mathbf{k}} \cdot \nabla \times \mathrm{HV}]$, and $(\mathrm{e}),(\mathrm{f})[(1 / \beta) \hat{\mathbf{k}} \cdot \nabla \times \mathrm{ADV}]$. Depth integrations are made to $1400 \mathrm{~m}$. The yellow border indicates the edge of the masked regions.

boundary condition that in a geostrophic flow BPT $=f w_{b}$, where $w_{b}$ is the vertical velocity at the bottom (Lu and Stammer 2004). Hence, any nonzero BPT can lead to vertical velocities and accordingly to vortex stretching.

We find that the deep transports in ECCO-GODAE are indeed largely induced by BPT (Fig. 6b). The BPT compares well to that from an eddy-permitting ocean model in terms of magnitude and spatial structure (Hughes and de Cuevas 2001) and supports past estimates of BPT in the deep subtropical ocean (Bryan et al. 1995; Hughes and de Cuevas 2001). If Eq. (2) was obtained by integrating to a depth below approximately $3 \mathrm{~km}$, then bottom vertical velocities induced by BPT would cause large domain-averaged pointwise Sverdrup errors even in the subtropical interior ocean (Fig. 1). The deep velocities in Fig. 6a, however, do not resemble the upper-layer ocean transports (Fig. 2a) or the Sverdrup errors (Fig. 4) contained between the surface and 1400-m depth. Therefore, although BPT has a significant impact on the vorticity in the deep ocean, the deep transports are mostly separated from the transports and Sverdrup errors of the upper ocean and are therefore not the root cause of the Sverdrup errors shown in Fig. 2e. It should be noted that regions of high BPT remain in calculations of the $1400-\mathrm{m}$ depth-integrated vorticity equation [Eq. (2)]. These are situated above topography 
(a)

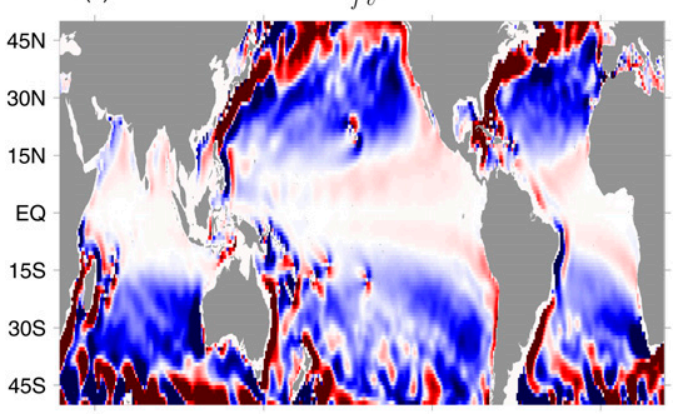

(c)

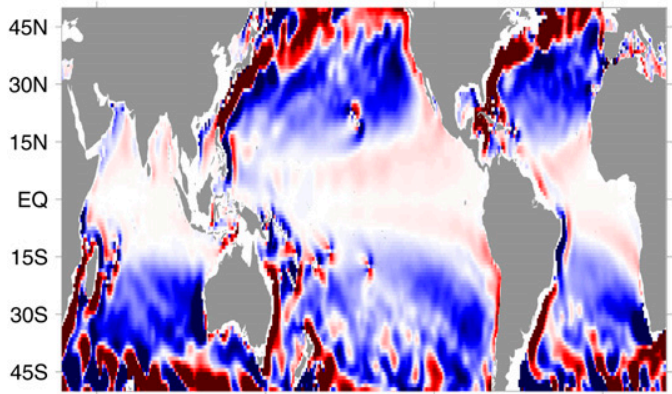

(e)

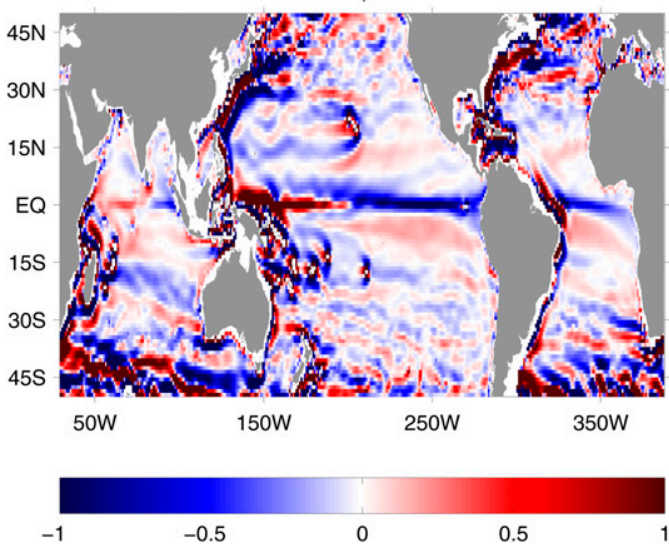

(b)

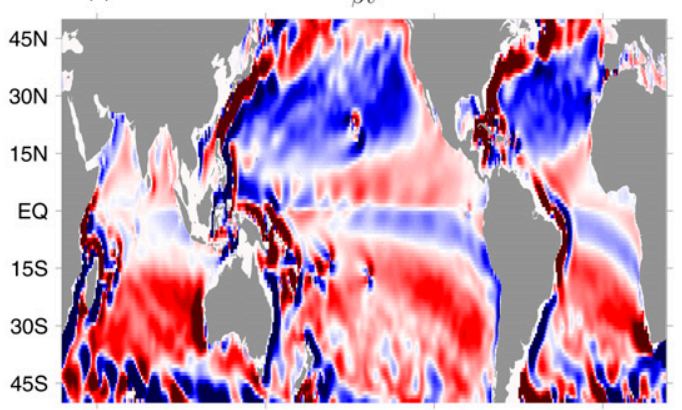

(d)

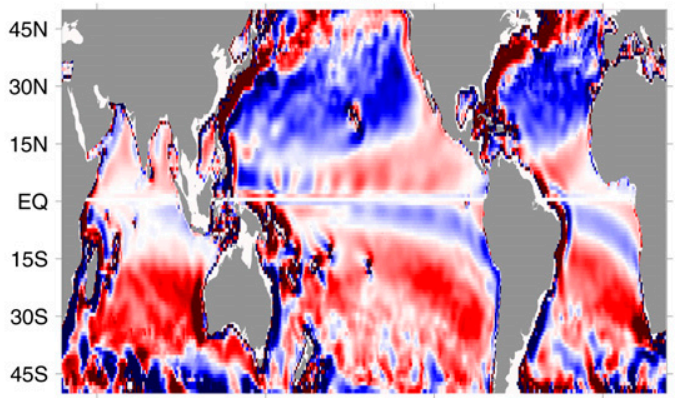

(f)

$\beta v \quad f \partial_{z} w$

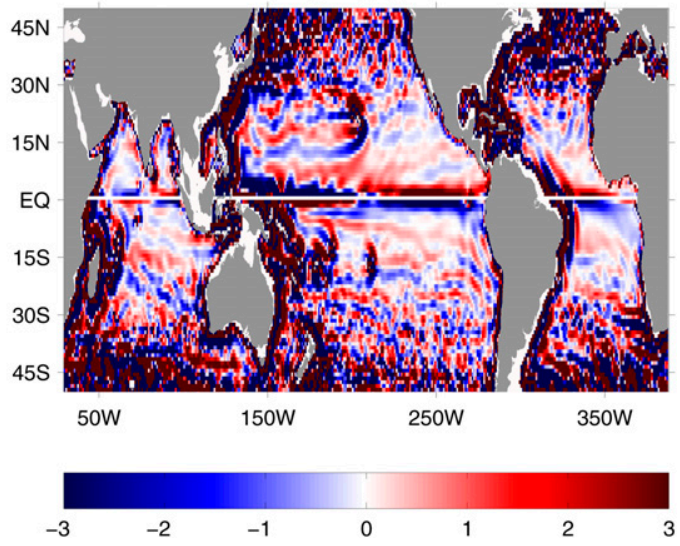

FIG. 5. The terms in the 15-yr time-averaged geostrophic equation in ECCO-GODAE at 310-m depth (a) fv $\left(10^{-6} \mathrm{~m} \mathrm{~s}^{-2}\right)$, (c) $-\left(1 / \rho_{0}\right) \partial_{x} p\left(10^{-6} \mathrm{~m} \mathrm{~s}^{-2}\right)$, and (e) their difference $\left(10^{-8} \mathrm{~m} \mathrm{~s}^{-2}\right)$. The terms in the 15 -yr timeaveraged linear vorticity equation at 310-m depth (b) $\beta v\left(10^{-13} \mathrm{~s}^{-2}\right)$, (d) $f \partial_{z} w\left(10^{-13} \mathrm{~s}^{-2}\right)$, and (f) their difference $\left(10^{-14} \mathrm{~s}^{-2}\right)$.

shallower than $1400 \mathrm{~m}$ and are confined to bands along eastern boundaries and around islands within the unmasked domain. Their contribution to the zonally and depth-integrated vorticity balance would be large in places; however, to avoid outliers biasing the results, their effects have largely been removed from calculations of integrated quantities following the removal of the largest $1 \%$ of the Sverdrup errors, as described in section $4 \mathrm{~b}$.

\section{Sverdrup balance in HiGEM}

We here use HiGEM to test the Sverdrup balance findings from ECCO-GODAE using a higher-resolution model and to investigate the temporal scales of Sverdrup balance in the 120 yearlong simulation.

\section{a. Spatial scales}

Figure 1b shows how the Sverdrup balance metrics change with the choice of integration depth when applied over a $15-\mathrm{yr}$ average of the unmasked subtropical domain of HiGEM. Years 105-120 are used to ensure that the model (the deep ocean in particular) is as close to equilibrium as possible, but note that the results are not strongly dependent on which 15 -yr period is considered. As with ECCO-GODAE, the initial reduction and subsequent increase in the metrics represent how an 


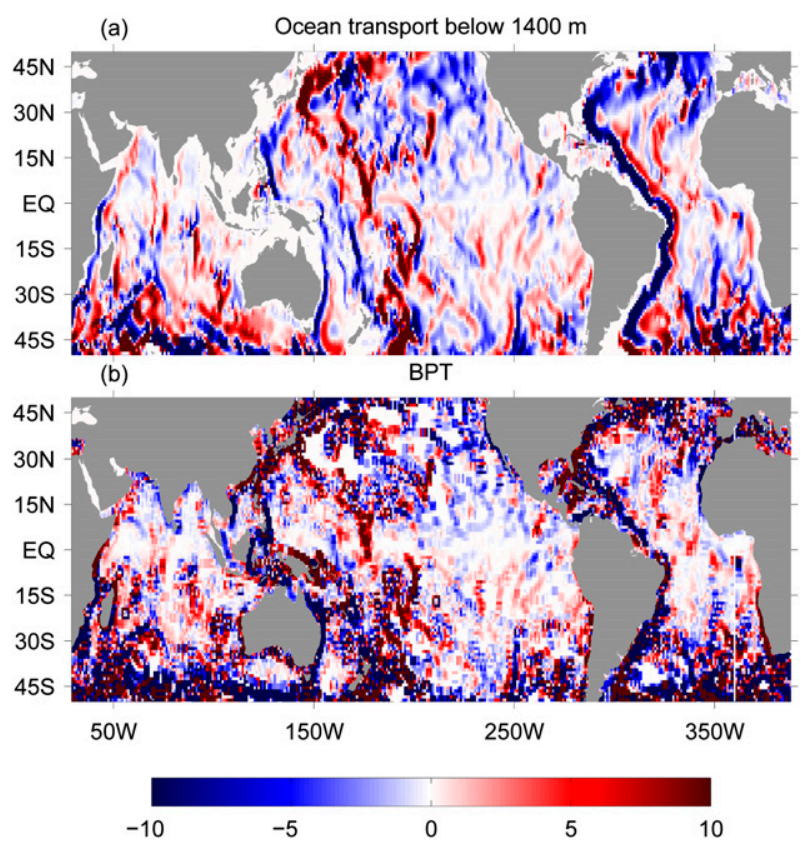

FIG. 6. (a) Meridional transport depth integrated from $1400 \mathrm{~m}$ to the bottom and (b) BPT in ECCO-GODAE $\left(\mathrm{m}^{2} \mathrm{~s}^{-1}\right)$. The BPT is smoothed at $3^{\circ}$ longitude by $3^{\circ}$ latitude.

increasing amount of the wind-driven layer is included in the depth integral before non-wind-driven deep transports are encountered that depreciate the balance. In HiGEM, Sverdrup balance holds slightly better than in ECCO-GODAE. The optimal values of $M_{\mathrm{pw}}$ are $48 \%$ in the unsmoothed data and $20 \%$ when smoothed at $5^{\circ}$, while $M_{\mathrm{zi}}$ is $14 \%$ and $11 \%$ in unsmoothed and smoothed data, respectively.

Deep transports in HiGEM are significantly stronger than in ECCO-GODAE, as indicated by the large unsmoothed values of $M_{\mathrm{pw}}$ below approximately $2-\mathrm{km}$ depth. As with ECCO-GODAE, deep transports in HiGEM correspond well with the BPT (not shown). Much of the deep transport cancels when smoothed at $5^{\circ}$, however, suggesting therefore that strong small-scale alternating transports exist in the deep ocean of HiGEM. If this variability is smaller than can be resolved by the coarser ECCO-GODAE grid then this would explain why the deep transports are so much stronger in HiGEM. Once smoothed or integrated, the variation of the metrics with increasing integration depth follows a very similar pattern in both models. This indicates that Sverdrup balance is similarly represented in the two models once the difference in their resolutions is accounted for by spatial averaging. The similar values and profiles of the Sverdrup metrics supports the conclusions reached using ECCOGODAE on the relevance of Sverdrup balance to describe the ocean circulation.
Sverdrup balance in HiGEM, calculated using 1000-m depth as a LONM (the optimal depth of the $5^{\circ}$ smoothed $M_{\mathrm{pw}}$ ), is shown in Fig. 2 (right panel). The large-scale features, as described in section 5b for ECCO-GODAE, are similar in both models and generally compare well to observations (Gray and Riser 2014). The regions where Sverdrup balance errors are large in the ocean, such as close to strong currents and near islands, are generally similarly represented in the two models. However, Sverdrup errors in HiGEM are, for the most part, smaller, but with patches of high discrepancy. In particular, Sverdrup errors are smaller in HiGEM near the poleward boundaries of the mask in comparison to ECCO-GODAE, especially in the mid- to high-latitude North Pacific where they are also smaller than estimations from Argo observations using the 26.24 potential density isopycnal (Gray and Riser 2014). Contrary to ECCO-GODAE, small-scale features are contained in the ocean component of HiGEM and not in the wind stress curl. Although the wind stress curl in the model is found to be affected by SST fronts (e.g., in the Southern Ocean; de Boer et al. 2013), as found in scatterometry measurements (Chelton et al. 2004), it is generally smoother in these areas in the model than in observations. The wind stress curl is, however, more realistic in HiGEM than in ECCO-GODAE (Fig. 2).

A full deconstruction of the vorticity equation cannot be made with the HiGEM data. This is because some nonlinear terms in the vorticity equation cannot be calculated using the available annual-mean output. However, the LONM term can be calculated and the LV component can subsequently be calculated as the residual (shown in section 3 of the supplementary material). We find the two error components to be more similar in HiGEM than in ECCO-GODAE, with $\Delta_{\mathrm{LV}}$ approximately 1.3 times larger than $\Delta_{\mathrm{LONM}}$ on average in the unmasked domain (according to the mean of the absolute values). As also found in ECCO-GODAE, this ratio does not change much in the interior domain following smoothing. Differences between the two models may be due to the adjoint method employed in ECCO-GODAE. In order for ECCO-GODAE to achieve dynamical consistency, the adjoint modifies the input data to achieve a solution that accounts for the observations within their ranges of uncertainty. It is possible therefore that model deficiencies have led to modifications of the wind stresses such that the curl becomes larger (Lu and Stammer 2004). For example, the ECCO-GODAE wind stress may have to adopt increased levels of small-scale noise in order to accommodate its high frictional dissipation of external forcing. This could then directly affect the LONM error through Ekman pumping of the vertical velocities. So while Sverdrup balance is found to hold similarly in the 

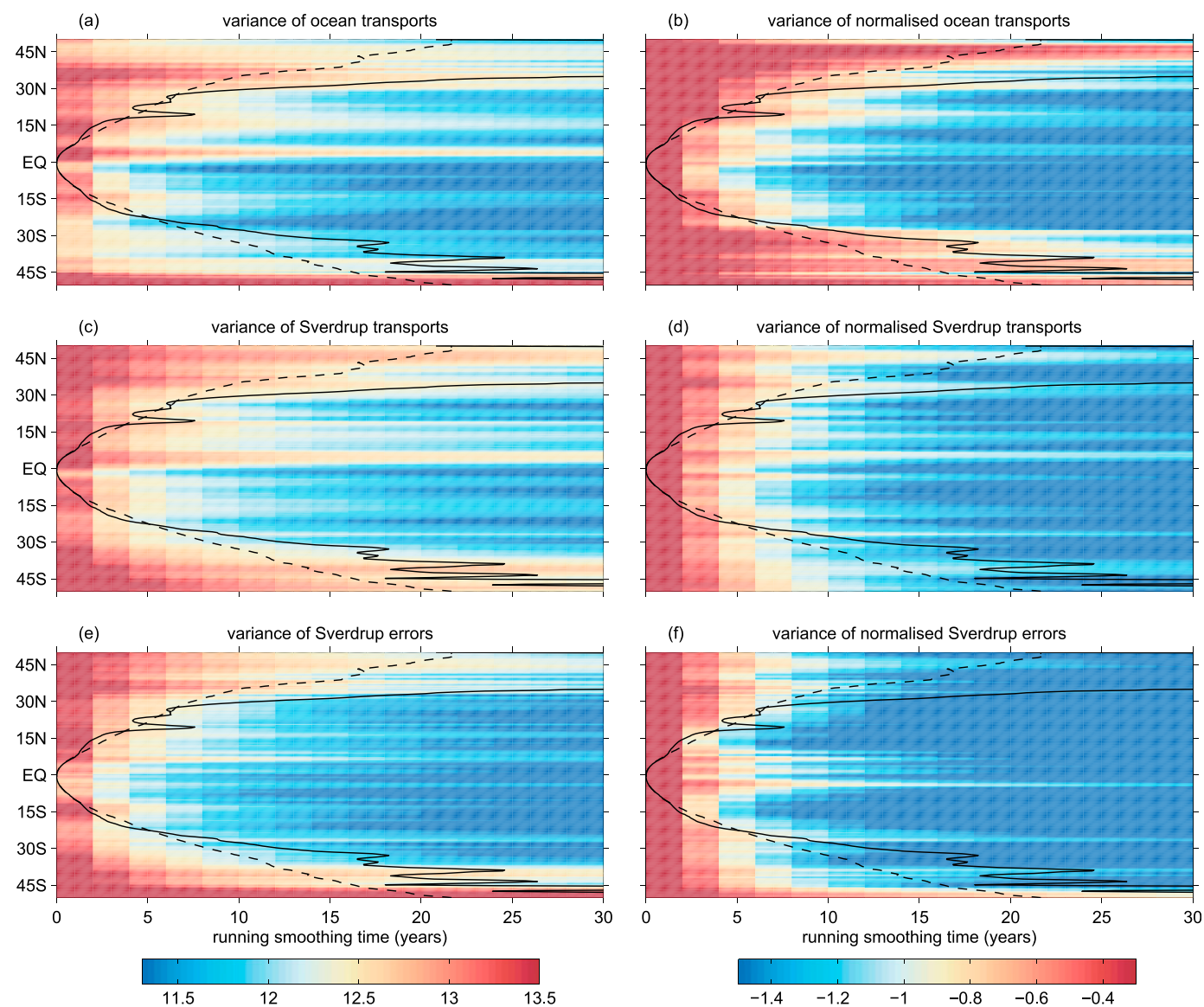

FIG. 7. Variance of the (left) original $\left[\log 10\left(\mathrm{~m}^{6} \mathrm{~s}^{-2}\right)\right]$ and (right) normalized $[\log 10$ (normalized units)] 1000-m depth-integrated HiGEM Pacific transports as a function of running smoothing time scale: (a),(b) ocean transports, (c),(d) Sverdrup transports, and (e),(f) Sverdrup errors. See text for details. The dashed and solid lines are respectively the basin-crossing times for Rossby waves with phase speed at the nondispersive dispersion limit (Tailleux and McWilliams 2001) and for flow-adjusted Rossby waves with speeds at the nondispersive phase speed minus the time-mean and zonal-mean zonal flow speed. The unsmoothed variance is equal to 1 at all latitudes (saturated to help show relative differences).

two models, the details of where the errors are contained may be more realistic in HiGEM.

\section{b. Temporal scales}

Here we investigate the time scale that gives an optimal Sverdrup balance. In other words, we investigate the time scale at which the time-dependent term becomes negligible in the vorticity balance. This is done in HiGEM since its output spans $120 \mathrm{yr}$ versus only $15 \mathrm{yr}$ for ECCOGODAE. Furthermore, unlike in ECCO-GODAE, both the wind field and the ocean fields are free to evolve naturally in HiGEM. The analysis is shown for the Pacific but conclusions hold also for the Atlantic.

To get an indication of the amplitude of variability of the ocean and Sverdrup transports, we have calculated the variance of the time series of zonally integrated (across the unmasked region) ocean transport and
Sverdrup transport at each latitude (Figs. 7a,c). For an indication of the frequency of the time series, they are smoothed with averaging windows ranging from 0 to $30 \mathrm{yr}$, and the variance is recalculated. The variance of both the ocean transport and Sverdrup transport (thus wind stress curl) is much higher at high latitudes than low latitudes (Figs. 7a,c). To compare the smoothing time window required to reduce the variance to a fraction (say $10 \%$ ) of the unsmoothed variance at that latitude the variance is normalized so that it is equal to one at each latitude when unsmoothed (Figs. 7b,d). Also with regard to the method, to avoid incremental reductions in the length of the time series with increasing averaging window size, time series were looped in time prior to smoothing and then the original data length was recovered after smoothing. The slower drop in variance with smoothing of the ocean transport at high latitudes indicates that the ocean 
transport has much lower-frequency variability at high latitudes than low latitudes (Fig. 7b). This is confirmed by the latitude-dependent spectra (verified but not shown). In contrast, high frequencies dominate the Sverdrup transport at all latitudes. Thus, while the wind forcing of the ocean has a high frequency at all latitudes, the ocean responds with a high frequency only at low latitudes.

The slower response of the ocean at high latitudes may be related to Rossby waves, which bring about ocean adjustment to wind forcing (Anderson and Killworth 1977). The basin-crossing time of first baroclinic mode Rossby waves increases with distance from the equator, as calculated from the theoretical nondispersive phase limit of Tailleux and McWilliams (2001; Fig. 7, dashed line). The dispersion theory has received support for its usefulness in numerical models (Hunt et al. 2012). The basin-crossing time is further lengthened if the Rossby wave speeds are reduced by the speed of the background eastward flow (Hughes and de Cuevas 2001; here depth averaged in the thermocline between approximately 60 and $160 \mathrm{~m}$; Fig. 7 , solid line). There seems to be a correspondence between the flow-adjusted basin-crossing time of the wave and the rate of decrease of the transport variance (Fig. 7b).

As may be expected from the above, the Sverdrup error, or difference in the ocean transport and the Sverdrup transport, is also highly variable at all latitudes (Fig. 7e). The Sverdrup error contains high frequencies at all latitudes, suggesting its variability is dominated by the wind component (Fig. 7f). Therefore, at time scales of about $5 \mathrm{yr}$ and longer, the Sverdrup error reaches a good long-term approximation (although this does not imply perfect Sverdrup balance).

Changes in the Sverdrup error with smoothing give an indication of how fast the ocean adjusts to the wind forcing, but it does not tell us how it relates to the actual transports and therefore to Sverdrup balance. This can be explored by relating the variance of the Sverdrup error to the variance of the zonally integrated ocean transports as a percentage variance ratio, $r=100[1-$ $\left.\operatorname{var}\left(\Delta_{\mathrm{SE}}\right) / \operatorname{var}(V)\right]$, calculated as a function of latitude and temporal smoothing. Here the operator var refers to the variance of the time series in brackets (Fig. 8). Initially for the unsmoothed annual time series, the variance of the Sverdrup error is higher than the ocean transport variance, and the variance ratio $r$ is negative. At the smoothing time scale where the variance of the Sverdrup error is equal to that of the Sverdrup transport, $r$ is $0 \%$, and the Sverdrup balance begins to be a useful indicator of the circulation. The time scale at which this comes about does not match the adjusted basin-crossing time scale of Rossby waves. At $100 \%$, the Sverdrup error variance is zero and all of the ocean variability can be explained by the wind stress curl variability.

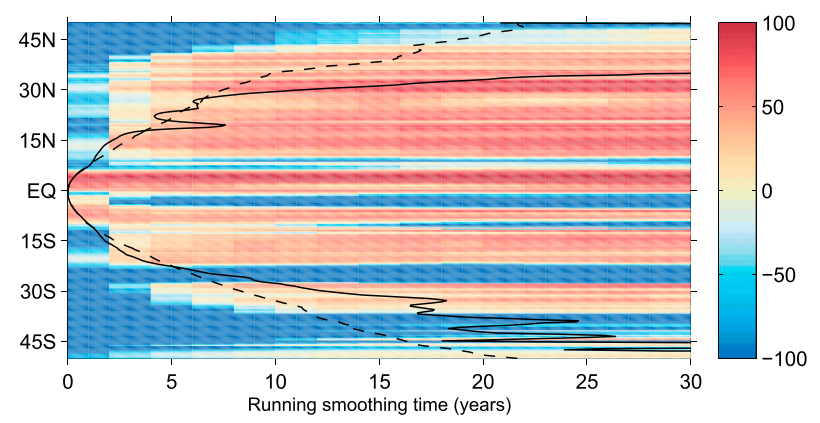

FIG. 8. The transport variance ratio, $r=100\left[1-\operatorname{var}\left(\Delta_{\mathrm{SE}}\right) / \operatorname{var}(V)\right]$, applied to the zonally integrated and depth-integrated (to $1000 \mathrm{~m}$ ) Pacific transports of HiGEM. The dashed and solid lines are respectively the basin-crossing times for Rossby waves with phase speed at the nondispersive dispersion limit (Tailleux and McWilliams 2001) and for flow-adjusted Rossby waves with speeds at the nondispersive phase speed minus the time-mean and zonal-mean zonal flow speed.

The discrepancy between the time scales of the adjusted Rossby wave propagation and the rate of change with the smoothing of the transport variance ratio $r$ is because smoothing has a stronger effect on highfrequency variability than on low-frequency variability. High frequencies contained in the Sverdrup error time series come mostly from the Sverdrup transport (Figs. $7 \mathrm{~b}, \mathrm{~d}$ ) and are large in the model (Figs. 7c,e). The rate of change in variance of the Sverdrup error time series with smoothing is therefore dominated by changes to the high frequencies, which predominantly reflect the change of the Sverdrup transport variability (which does not change according to Rossby waves). This rate of change is also manifested in the variance ratio $r$, since it comes about faster than that from smoothing the lower-frequency ocean transport time series.

Another way to understand the temporal scale of Sverdrup balance is to relate the adjustment of the variability of the transports to their magnitude. If the transport variability is small in comparison to the mean transports, then a more practical Sverdrup balance might be found at short time scales. We find this to be the case in HiGEM throughout the subtropics, which we have determined by comparing the 15 -yr mean zonally integrated Pacific transports to the transport standard deviation of the full 120-yr time series at each latitude (Fig. 9). Even at unsmoothed annual time scales, the transport variability is small in comparison to the mean transports at most latitudes. At 5-yr smoothing, the variability is everywhere very small (dotted lines). This is true even where Sverdrup balance breaks down, such as near the equator (Fig. 9) and in the Southern Ocean (not shown), where the breakdown occurs not because of high variability but due to the ocean and Sverdrup transports having different time-mean structures. The temporal 


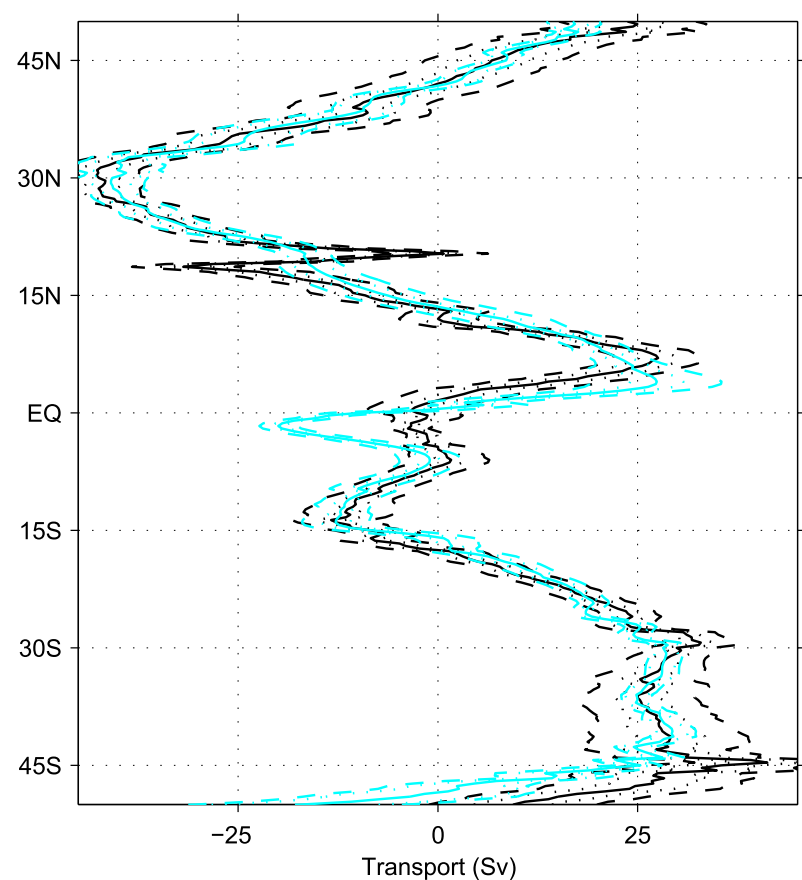

FIG. 9. The 15-yr time-mean (years 105-120) HiGEM zonally integrated Pacific transport Sverdrup balance terms (Sv): $V$ (using an integration depth of $1000 \mathrm{~m}$; solid cyan line) and $\left(1 / \rho_{0} \beta\right) \hat{\mathbf{k}} \cdot \nabla \times \boldsymbol{\tau}_{s}$ (solid black line) vs latitude. The dashed and dotted lines respectively represent the 15 -yr time-mean plus and minus the 120 -yr transport variance at unsmoothed and 5-yr smoothed time scales.

adjustment of the ocean transports therefore has only a small impact on zonally integrated Sverdrup balance in HiGEM, meaning that a practical use of Sverdrup balance can be used over the subtropics before the ocean transports have fully adjusted to wind forcing. Recent observational estimates of the zonally integrated upper-ocean transport from the Rapid Climate Change (RAPID) array at $26^{\circ} \mathrm{N}$ in the Atlantic also find that its interannual variability is small compared to its mean value (McCarthy et al. 2012), which, together with observational evidence that Sverdrup balance holds in the real ocean (Gray and Riser 2014), suggests this result could be robust.

\section{Conclusions}

A detailed analysis of Sverdrup balance using both the ECCO-GODAE state estimate and the HiGEM eddy-permitting coupled climate model has been presented. We have demonstrated that Sverdrup balance holds to a good order of approximation in the interior subtropical ocean domain when using a middepth integration level and when considered over horizontal scales greater than approximately $5^{\circ}$ and time-averaging scales of a few years or more. On large scales, the ocean transport seems to adjust at the basin-crossing time scale of first baroclinic mode Rossby waves that are arrested by the zonal-mean flow. However, the ocean transport variability is found to be small compared to the time mean and its adjustment time scales are therefore found to be of relative unimportance.

To assess how well Sverdrup balance holds, we have used two metrics $M_{\mathrm{pw}}$ and $M_{\mathrm{zi}}$ that are respectively local and zonal average measures of the balance between the actual ocean transport and the Sverdrup transport derived from the wind stress curl field. In ECCOGODAE, using an optimized integration depth plane of $1400 \mathrm{~m}$, the pointwise Sverdrup metric $M_{\mathrm{pw}}$ is $31 \%$ (the magnitude of the Sverdrup errors considered as a fraction of the magnitude of the Sverdrup transports) when evaluated over interior subtropical transports that are smoothed at scales of $5^{\circ}$. When transports are first zonally integrated across the interior ocean, the Sverdrup errors are only $20 \%$ of the magnitude of the Sverdrup transport, according to a zonally integrated metric $M_{\mathrm{zi}}$. For transport fields that are smoothed by $5^{\circ}, M_{\mathrm{zi}}$ improves to $12 \%$. Such a value is particularly relevant for simplified theories of the large-scale circulation that rely on Sverdrup balance. At unsmoothed spatial scales of $1^{\circ}$, variability that is present in the wind stress curl but not in the ocean transport invalidates Sverdrup balance by increasing $M_{\mathrm{pw}}$ to $56 \%$. The Sverdrup error is due to the combined errors resulting from the assumptions that (i) there is a LONM to integrate to and (ii) the ocean vorticity is linear. The LONM error is about a factor of 2 larger than the linear vorticity error when a LONM is chosen at 1400-m depth. The metrics have been calculated using the transports from the full global interior subtropical domain, although they represent quite well the values obtained when using just the Atlantic and Indian Oceans transports. Sverdrup balance provides a worse approximation of the transports in the Pacific, however, with $M_{\mathrm{pw}}$ and $M_{\mathrm{zi}}$ worsening to $61 \%$ and $33 \%$, respectively, when calculated using unsmoothed transports.

These findings are complemented by an analysis of a 15-yr time-mean of HiGEM output, in which the optimum $M_{\mathrm{pw}}$ is $20 \%$ at scales of $5^{\circ}$ and $M_{\mathrm{zi}}$ is $14 \%$. In HiGEM, Sverdrup balance also does not hold well when considered on a pointwise basis. It can be concluded from the two models that the large-scale subtropical circulation (and its future evolution; Thomas et al. 2012) can be obtained to the first order on decadal time scales from linear theory via Sverdrup balance.

In ECCO-GODAE, the results are largely unaffected by different choices of integration depth. These include the use of a more complicated geovarying depth, such as the depth of an isopycnal or a mapped depth of small velocity. So long as the integration depth is everywhere deeper than the main body of the thermocline, but not so 
deep as to impinge too greatly on deep currents, then the results are not found to vary greatly with the choice of LONM.

The extent to which the results can be interpreted as applicable to the real ocean is complicated by inadequacies in model physics, the impacts of which can only be speculated on. One influence on the Sverdrup error is the strength of the deep-ocean circulation, which in most models is inaccurate (Wunsch 2011). In ECCO-GODAE, the strength of the time-mean North Atlantic Deep Water is more than 5 Sverdrups (Sv; $1 \mathrm{~Sv} \equiv 10^{6} \mathrm{~m}^{3} \mathrm{~s}^{-1}$ ) weaker than that deduced from the RAPID-Meridional Overturning Circulation and Heatflux Array (MOCHA) at $26.5^{\circ} \mathrm{N}$, and the meridional overturning circulation is accordingly too weak (Baehr et al. 2009). If the deep circulation was stronger and its structure unchanged (e.g., the proportion of cross isobath flow were to remain the same), then the BPT should increase proportionately. Calculations of BPT in ECCOGODAE are therefore likely to be an underestimate of that in the real ocean. However, deep transports in HiGEM are stronger than those in ECCO-GODAE, and the overturning compares favorably with observations (Shaffrey et al. 2009), yet Sverdrup balance holds in the upper ocean of the model to a similar extent as to ECCO-GODAE and to observations made from Argo data (Gray and Riser 2014). It is possible therefore that stronger deep transports in ECCO-GODAE would not change the main conclusions drawn from it. At $1^{\circ}$ resolution, ECCO-GODAE does not resolve ocean eddies and requires an unrealistically high horizontal viscosity to achieve numerical stability (Griffies 2004). This may mean that the curl of horizontal viscosity $[(1 / \beta) \hat{\mathbf{k}}$. $\nabla \times \mathrm{HV}]$ in the real ocean is smaller than that presented here, and the curl of advection $[(1 / \beta) \hat{\mathbf{k}} \cdot \nabla \times \mathrm{ADV}]$ is larger. The effect on calculations of Sverdrup balance, however, is unclear since there may be a simple trade-off between the contributions of the HV and ADV terms to the Sverdrup error.

The fact that Sverdrup balance holds to a similar extent in both models suggests that a shift to higherresolution results in a similar magnitude Sverdrup error but a trade-off in the dominant contributor to this error. An estimation of the linear vorticity and LONM errors in HiGEM indicates that the magnitude of the LV error is approximately 1.3 times larger than the LONM error, as opposed to ECCO-GODAE in which the LONM errors are approximately 2 times larger than the LV errors. The correspondingly weaker vertical velocities are consistent with the weaker spatial variability in the wind stress curl seen in HiGEM, and the larger linear vorticity error is consistent with the smaller-scale ocean transports. So while the major conclusions on Sverdrup balance appear to be robust, some of the details differ depending on how the small scales are handled. Given potential problems introduced by the adjoint methodology employed by ECCO-GODAE (Lu and Stammer 2004), we suggest that the details are more accurately represented in HiGEM.

The impacts of the results are several fold. The ocean theories that incorporate Sverdrup balance as an underlying basis can now be better appreciated in terms of the extent to which they might hold on varying space and time scales. In particular, those that consider the timemean ocean on spatial scales exceeding about $5^{\circ}$ are well supported by our findings. Furthermore, in light of climatic changes that are predicted to take place over the coming century the results suggest that Sverdrup balance may be used as a potential tool to estimate the interior ocean circulation on climate relevant time scales from satellite measurements of wind stress, to interpret and constrain existing measurements of the ocean circulation, and to derive theories of the future evolution of the ocean using linear dynamics.

Acknowledgments. The HiGEM coupled climate model was developed from the Met Office Hadley Centre Model by the U.K. High-Resolution Modelling (HiGEM) Project and the U.K. Japan Climate Collaboration (UJCC). HiGEM is supported by a NERC HighResolution Climate Modelling Grant (R8/H12/123). UJCC was supported by the Foreign and Commonwealth Office Global Opportunities Fund and jointly funded by NERC and the DECC/Defra Met Office Hadley Centre Climate Programme (GA01101). The model integrations were performed using the Japanese Earth Simulator supercomputer, supported by JAMSTEC. The work of Professor Pier Luigi Vidale and Dr. Malcolm Roberts in leading the effort in Japan is particularly valued. Computations were carried out on the High Performance Computing Cluster supported by the Research Computing Service at the University of East Anglia. We are very grateful to Patrick Heimbach for his help with the ECCOGODAE model. We also thank Arnaud Czaja, Xiaoming Zhai, Carl Wunsch, Laure Zanna and David Marshall for useful discussions and comments. We thank Dudley Chelton for providing the dispersion relations of Tailleux and McWilliams (2001). Constructive comments from two reviewers were much appreciated. HLJ is funded by a Royal Society University Research Fellowship, for which she is grateful.

\section{REFERENCES}

Anderson, D. L. T., and P. D. Killworth, 1977: Spin-up of a stratified ocean, with topography. Deep-Sea Res., 24, 709-732, doi:10.1016/0146-6291(77)90495-7. 
Aoki, K., and K. Kutsuwada, 2008: Verification of the wind-driven transport in the North Pacific subtropical gyre using gridded wind-stress products. J. Oceanogr., 64, 49-60, doi:10.1007/ s10872-008-0004-6.

Baehr, J., S. Cunnningham, H. Haak, P. Heimbach, T. Kanzow, and J. Marotzke, 2009: Observed and simulated estimates of the meridional overturning circulation at $26.5^{\circ} \mathrm{N}$ in the Atlantic. Ocean Sci., 5, 575-589, doi:10.5194/os-5-575-2009.

Böning, C. W., R. Döscher, and H. J. Isemer, 1991: Monthly mean wind stress and Sverdrup transports in the North Atlantic: A comparison of the Hellerman-Rosenstein and Isemer-Hasse climatologies. J. Phys. Oceanogr., 21, 221-235, doi:10.1175/ 1520-0485(1991)021<0221:MMWSAS > 2.0.CO;2.

Bryan, F. O., C. W. Böning, and W. R. Holland, 1995: On the midlatitude circulation in a high-resolution model of the North Atlantic. J. Phys. Oceanogr., 25, 289-305, doi:10.1175/ 1520-0485(1995)025<0289:OTMCIA $>2.0 . C O ; 2$.

Chelton, D. B., M. G. Schlax, M. H. Freilich, and R. F. Milliff, 2004: Satellite measurements reveal persistent small-scale features in ocean winds. Science, 303, 978-983, doi:10.1126/ science. 1091901.

Conkright, M. E., R. A. Locarnini, H. E. Garcia, T. D. O'Brien, T. P. Boyer, C. Stephen, and J. I. Antonov, 2002: World Ocean Atlas 2001: Objective Analyses, Data Statistics, and Figures. CD-ROM documentation, National Oceanographic Data Center Internal Rep. 17, 17 pp. [Available online at ftp:// ftp.nodc.noaa.gov/pub/WOA01/readme.pdf.]

de Boer, A. M., and H. L. Johnson, 2007: Inferring the zonal distribution of measured changes in the meridional overturning circulation. Ocean Sci., 3, 55-57, doi:10.5194/os-3-55-2007.

—, R. M. Graham, M. D. Thomas, and K. E. Kohfeld, 2013: The control of the Southern Hemisphere westerlies on the position of the subtropical front. J. Geophys. Res. Oceans, 118, 56695675, doi:10.1002/jgrc.20407.

Gent, P. R., W. G. Large, and F. O. Bryan, 2001: What sets the mean transport through Drake Passage? J. Geophys. Res., 106, 2693-2712, doi:10.1029/2000JC900036.

Godfrey, J. S., and T. J. Golding, 1981: The Sverdrup relation in the Indian Ocean, and the effect of Pacific-Indian Ocean Throughflow on Indian Ocean circulation and on the East Australian Current. J. Phys. Oceanogr., 11, 771-779, doi:10.1175/ 1520-0485(1981)011<0771:TSRITI >2.0.CO;2.

Gray, A. R., and S. C. Riser, 2014: A global analysis of Sverdrup balance using absolute geostrophic velocities from Argo. J. Phys. Oceanogr., 44, 1213-1229, doi:10.1175/JPO-D-12-0206.1.

Griffies, S. M., 2004: Fundamentals of Ocean Climate Models. Princeton University Press, 518 pp.

Hautala, S. L., D. H. Roemmich, and W. J. Schmitz, 1994: Is the North Pacific in Sverdrup balance along $24^{\circ}$ N. J. Geophys. Res., 99, 16041-16052, doi:10.1029/94JC01084.

Hughes, C. W., and B. A. de Cuevas, 2001: Why western boundary currents in realistic oceans are inviscid: A link between form stress and bottom pressure torques. J. Phys. Oceanogr., 31, 2871-2885, doi:10.1175/1520-0485(2001)031<2871 WWBCIR $>2.0 . \mathrm{CO} ; 2$.

Hunt, F. K., R. Tailleux, and J. J. M. Hirschi, 2012: The vertical structure of oceanic Rossby waves: A comparison of highresolution model data to theoretical vertical structures. Ocean Sci., 8, 19-35, doi:10.5194/os-8-19-2012.

Jiang, H., H. Wang, J. Zhu, and B. Tan, 2006: Relationship between real meridional volume transport and Sverdrup transport in the north subtropical Pacific. Chin. Sci. Bull., 51, 1757-1760, doi:10.1007/s11434-006-2031-2.
Johns, T. C., and Coauthors, 2006: The new Hadley Centre Climate Model (HadGEM1): Evaluation of coupled simulations. J. Climate, 19, 1327-1353, doi:10.1175/JCLI3712.1.

Josey, S. A., E. C. Kent, and P. K. Taylor, 2002: Wind stress forcing of the ocean in the SOC climatology: Comparisons with the NCEP-NCAR, ECMWF, UWM/COADS, and Hellerman and Rosenstein datasets. J. Phys. Oceanogr., 32, 1993-2019, doi:10.1175/1520-0485(2002)032<1993:WSFOTO>2.0.CO;2.

Kessler, W. S., G. C. Johnson, and D. W. Moore, 2003: Sverdrup and nonlinear dynamics of the Pacific equatorial currents. J. Phys. Oceanogr., 33, 994-1008, doi:10.1175/1520-0485(2003)033<0994: SANDOT $>2.0 . \mathrm{CO} ; 2$.

Landsteiner, M. C., M. J. McPhaden, and J. Picaut, 1990: On the sensitivity of Sverdrup transport estimates to the specification of wind stress forcing in the tropical Pacific. J. Geophys. Res., 95, 1681-1691, doi:10.1029/JC095iC02p01681.

Large, W. G., J. C. McWilliams, and S. C. Doney, 1994: Oceanic vertical mixing: A review and a model with a nonlocal boundary-layer parameterization. Rev. Geophys., 32, 363-403, doi:10.1029/94RG01872.

Leetmaa, A., and A. F. Bunker, 1978: Updated charts of mean annual wind stress, convergences in Ekman layers, and Sverdrup transports in North Atlantic. J. Mar. Res., 36, 311-322.

P. Niiler, and H. Stommel, 1977: Does the Sverdrup relation account for the mid-Atlantic circulation. J. Mar. Res., 35, 1-10.

Lu, Y. Y., and D. Stammer, 2004: Vorticity balance in coarseresolution global ocean simulations. J. Phys. Oceanogr., 34, 605-622, doi:10.1175/2504.1.

Luyten, J. R., J. Pedlosky, and H. Stommel, 1983: The ventilated thermocline. J. Phys. Oceanogr., 13, 292-309, doi:10.1175/ 1520-0485(1983)013<0292:TVT >2.0.CO;2.

- H. Stommel, and C. Wunsch, 1985: A diagnostic study of the northern Atlantic subpolar gyre. J. Phys. Oceanogr., 15, 1344-1348, doi:10.1175/1520-0485(1985)015<1344:ADSOTN>2.0.CO;2.

Marotzke, J., R. Giering, K. Q. Zhang, D. Stammer, C. Hill, and T. Lee, 1999: Construction of the adjoint MIT ocean general circulation model and application to Atlantic heat transport sensitivity. J. Geophys. Res., 104, 29 529-29547, doi:10.1029/ 1999JC900236.

Marshall, J., C. Hill, L. Perelman, and A. Adcroft, 1997: Hydrostatic, quasi-hydrostatic, and nonhydrostatic ocean modeling. J. Geophys. Res., 102, 5733-5752, doi:10.1029/96JC02776.

McCarthy, G., and Coauthors, 2012: Observed interannual variability of the Atlantic meridional overturning circulation at $26.5^{\circ}$ N. Geophys. Res. Lett., 39, L19609, doi:10.1029/ 2012GL052933.

Pedlosky, J., 1987: Geophysical Fluid Dynamics. 2nd ed. SpringerVerlag, $710 \mathrm{pp}$.

Roberts, M. J., and Coauthors, 2009: Impact of resolution on the tropical Pacific circulation in a matrix of coupled models. J. Climate, 22, 2541-2556, doi:10.1175/2008JCLI2537.1.

Roemmich, D., and C. Wunsch, 1985: Two transatlantic sections: Meridional circulation and heat flux in the subtropical North Atlantic Ocean. Deep-Sea Res., 32, 619-664, doi:10.1016/ 0198-0149(85)90070-6.

Schmitz, W. J., J. D. Thompson, and J. R. Luyten, 1992: The Sverdrup circulation for the Atlantic along $24^{\circ}$ N. J. Geophys. Res., 97, 7251-7256, doi:10.1029/92JC00417.

Shaffrey, L. C., and Coauthors, 2009: U.K. HiGEM: The new U.K. High-Resolution Global Environment Model-Model description and basic evaluation. J. Climate, 22, 1861-1896, doi:10.1175/2008JCLI2508.1. 
Stommel, H., 1948: The westward intensification of wind-driven ocean currents. Trans. Amer. Geophys. Union, 29, 202-206.

- P. Niiler, and D. Anati, 1978: Dynamic topography and recirculation of the North Atlantic. J. Mar. Res., 36, 449-468.

Sverdrup, H. U., 1947: Wind-driven currents in a baroclinic ocean: With application to the equatorial currents of the eastern Pacific. Proc. Natl. Acad. Sci. USA, 33, 318-326, doi:10.1073/ pnas.33.11.318.

Tailleux, R., and J. C. McWilliams, 2001: The effect of bottom pressure decoupling on the speed of extratropical, baroclinic Rossby waves. J. Phys. Oceanogr., 31, 1461-1476, doi:10.1175/ 1520-0485(2001)031<1461:TEOBPD>2.0.CO;2.

Thomas, M. D., A. M. de Boer, D. P. Stevens, and H. L. Johnson, 2012: Upper ocean manifestations of a reducing meridional overturning circulation. Geophys. Res. Lett., 39, L16609, doi:10.1029/2012GL052702.
Townsend, T. L., H. E. Hurlburt, and P. J. Hogan, 2000: Modeled Sverdrup flow in the North Atlantic from 11 different wind stress climatologies. Dyn. Atmos. Oceans, 32, 373-417, doi:10.1016/S0377-0265(00)00052-X.

Wunsch, C., 2011: The decadal mean ocean circulation and Sverdrup balance. J. Mar. Res., 69, 417-434, doi:10.1357/ 002224011798765303.

— and D. Roemmich, 1985: Is the North Atlantic in Sverdrup balance. J. Phys. Oceanogr., 15, 1876-1880, doi:10.1175/ 1520-0485(1985)015<1876:ITNAIS > 2.0.CO;2.

— , and P. Heimbach, 2007: Practical global oceanic state estimation. Physica D, 230, 197-208, doi:10.1016/j.physd.2006.09.040.

Zhang, R., and G. K. Vallis, 2007: The role of bottom vortex stretching on the path of the North Atlantic western boundary current and on the northern recirculation gyre. J. Phys. Oceanogr., 37, 2053-2080, doi:10.1175/JPO3102.1. 